\title{
Abnormal body composition, cardiovascular endurance, and muscle strength in pediatric SLE
}

\author{
Sangeeta Sule ${ }^{1 *}$ (D) and Kevin Fontaine ${ }^{2}$
}

\begin{abstract}
Background: Children with SLE are known to have higher fat mass compared to their peers but there are no published data regarding exercise capacity as measured by cardiovascular endurance and muscle strength. In our pilot study of ten children with SLE, we sought to examine body composition, cardiovascular endurance, and isometric muscle strength.

Findings: Ten pediatric SLE patients were studied with a mean age of 15.5 years and $90 \%$ female. Percent body fat above $30 \%$, the recommended normal level in adolescent females, were found in $89 \%$ of female subjects and $40 \%$ of all participants had lower than the recommended norms of muscle mass for their age/gender. Subjects with renal disease were more likely to have low muscle mass compared to those without renal disease $(p=0.03)$. Cardiovascular endurance was reported as estimated maximal oxygen consumption $\left(\mathrm{VO}_{2} \mathrm{max}\right)$ during cycle ergometry. All participants scored in less than fifth percentile for $\mathrm{VO}_{2}$ max measurements compared to data from age and gender matched published norms. Isokinetic muscle strength testing was performed on upper and lower extremities. Only one participant (male subject) reached goal percentiles for age and gender.
\end{abstract}

Conclusions: We found significant deficit in body composition, muscle strength and cardiovascular endurance in the pediatric SLE population compared to reported published norms. Clinicians should consider these data and focus on exercise programs that can increase aerobic capacity and muscle strength in this high-risk population.

Abbreviations: ACR, American College of Rheumatology; BMI, Body mass index; CAD, Coronary artery disease; CDC, Centers for disease control and prevention; CV, Cardiovascular; DEXA, Dual energy x-ray absorptiometry; dsDNA, Double-stranded deoxyribonucleic acid; SD, Standard deviation; SLE, Systemic lupus erythematosus;

SLEDAl, Systemic lupus erythematosus disease activity index scores; $\mathrm{VO}_{2}$ max, Estimated maximal oxygen consumption

\section{Background}

Patients with systemic lupus erythematosus (SLE) are considered to be at higher risk for early atherosclerosis and coronary artery disease (CAD), independent of traditional risk factor such as hypertension and smoking [1-6]. In order to lessen this risk, we encourage our patients to engage in exercise and physical activity. This increased activity may also improve overall quality of life, fatigue, pain, and emotional well-being [7].

SLE patients may experience difficulties when trying to become more active; for example, adults with SLE are

\footnotetext{
* Correspondence: ssule@jhmi.edu

${ }^{1}$ Department of Pediatrics, Johns Hopkins University, 200 N. Wolfe Street,

Suite 2126, Baltimore, MD 21287, USA

Full list of author information is available at the end of the article
}

known to have decreased cardiovascular endurance, lower muscle strength, and lower lean muscle mass compared to age-matched controls $[8,9]$. Children with SLE are known to have higher fat mass compared to their peers; lower lean muscle mass in these children has been associated with complications such as vertebral fractures [10-14]. In our pilot study, we sought to examine body composition, cardiovascular (CV) endurance, and isometric muscle strength in ten pediatric patients with SLE.

\section{Findings \\ Subjects}

Institutional review board (IRB) approval was obtained. Guardians were consented and youth were assented for participation in the study. The participants were recruited 
from consecutive pediatric SLE patients, defined as age $\leq 18$ years at SLE onset, seen at the Johns Hopkins Children's Center. We excluded patients with active arthritis or active myositis because the participants needed to be able to pedal without restrictions on the cycle ergometry for assessment of CV endurance. Participants with a past history of either arthritis or myositis were permitted. Of the 15 consecutive pediatric SLE patients, four had active arthritis and one had active myositis, leaving ten pediatric SLE patients in this pilot study. All patients met the American College of Rheumatology (ACR) criteria for SLE $[15,16]$.

\section{Measures}

At study entry, demographic data including age at enrollment, age at lupus diagnosis, gender, and race, were collected. Clinical and laboratory data were collected at the participant's outpatient rheumatology clinic appointment within 4 weeks of the study visit and were reported as present if seen at that visit. Systemic lupus erythematosus disease activity index scores (SLEDAI) scores were calculated based on these data [17].

We assessed perception of physical fitness by asking participants about their daily physical activity and whether they would consider themselves physically active over the past year. We assessed the duration in minutes for each physical activity per week, not including required school gym participation.

Total body lean and fat mass were assessed by assessed by dual energy X-ray absorptiometry (DEXA) (GE Lunar Prodigy, Software V. 13). Body weight and height were obtained by measurement at the time of the study visit. Patients were divided into age-adjusted categories for overweight and obese. Definitions for normal ranges of BMI were per the Centers for Disease Control and Prevention $(\mathrm{CDC})$ guidelines: normal; $<85^{\text {th }}$ percentile; overweight, $85-95^{\text {th }}$ percentile; obese, $>95^{\text {th }}$ percentile. The CDC recommended levels for adolescents are $<30 \%$ of total body composition body fat and $>60 \%$ lean muscle mass.

$\mathrm{CV}$ endurance capacity was assessed using peak oxygen uptake $\left(\mathrm{VO}_{2}\right.$ peak) during cycle ergometry. A Cardinal Health Vmax metabolic system was used to assess oxygen uptake while the participants pedaled on the stationary bicycle. The initial workload was set at $0 \mathrm{~W}$ and was increased by $20 \mathrm{~W}$ every $3 \mathrm{~min}$ until participants noted fatigue. Normal values were obtained from published reference data in adolescents and varied based on age and gender of the comparative SLE participant [18-21].

A Biodex unit was used to measure isometric muscle strength using peak isokinetic torques of elbow extension and flexion at 60 and 120 degrees/second, adjusted for body weight. Normative elbow values were obtained from reference data published by Biodex and ranged from 23 to $30 \%$ peak torque/body weight for 60 degrees/second and 13-24 \% peak torque/body weight for 120 degrees/second.
Knee peak isokinetic torques were obtained at 60 and 180 degrees/second. Normal knee ranges were $80-95 \%$ peak torque/body weight for 60 degrees/second movement and 50-65\% peak torque/body weight for 180 degrees/second movement.

\section{Statistical analyses}

We performed two-sided, unpaired t-tests for comparison of means and Fisher's exact tests for comparison of groups between our cohort and published reference data for categorical body composition data, continuous $\mathrm{CV}$ endurance data, and continuous muscle strength data $[18,20,22]$. Simple linear regression analyses were used to determine predictors of body composition and $\mathrm{CV}$ endurance via $\mathrm{VO} 2$ peak during cycle ergometry. We did not attempt multiple regression for these analyses as there were too few variables/subjects. Significance levels were set at a $p$-value $<0.05$.

\section{Results}

Demographic characteristics are shown in Table 1. Selfreported physical activity was high in our cohort. Eighty percent of patients reported that they would consider themselves physically active over the past year. Sixty

Table 1 Patient characteristics at study entry

\begin{tabular}{|c|c|}
\hline Characteristic & Value \\
\hline Age, mean (SD) & $15.5(3.1)$ \\
\hline Female gender, $n(\%)$ & $9(90 \%)$ \\
\hline African American, $n(\%)$ & $8(80 \%)$ \\
\hline Mean years with SLE, (SD) & $4.2(2.3)$ \\
\hline Malar rash, $n(\%)$ & $6(60 \%)$ \\
\hline Kidney disease, $n$ (\%) & $5(50 \%)$ \\
\hline Focal proliferative, $n(\%)$ & $1(10 \%)$ \\
\hline Membranous, $n$ (\%) & $1(10 \%)$ \\
\hline Diffuse proliferative, $n$ (\%) & $3(30 \%)$ \\
\hline ANA positive, $n(\%)$ & $10(100 \%)$ \\
\hline dsDNA positive, $n(\%)$ & $9(90 \%)$ \\
\hline Ro/La positive, $n$ (\%) & $2(20 \%)$ \\
\hline Smith positive, $n(\%)$ & $3(30 \%)$ \\
\hline Low C3/C4, n (\%) & $2(20 \%)$ \\
\hline Elevated ESR/CRP, $n(\%)$ & $0(0 \%)$ \\
\hline Anemia, $n(\%)$ & $0(0 \%)$ \\
\hline Prednisone & $4(40 \%)$ \\
\hline Dose & $0.1-0.5 \mathrm{mg} / \mathrm{kg} / \mathrm{day}$ \\
\hline Duration, mean months, (SD) & $2(3.1)$ \\
\hline Hydroxychloroquine, $n$ (\%) & $10(100 \%)$ \\
\hline Methotrexate, $n(\%)$ & $2(20 \%)$ \\
\hline Mycophenolate mofetil, n (\%) & $4(40 \%)$ \\
\hline
\end{tabular}


percent noted that they participated in physical activity 1-3 days per week for 30-60 min, $20 \%$ participated 4-6 days/week for 0-30 min, and $20 \%$ no exercise.
Fifty percent of participants were above recommended BMI guidelines. Mean BMI was $23.7 \mathrm{~kg} / \mathrm{m} 2$ (range 17.1$31.3 \mathrm{~kg} / \mathrm{m} 2$ ). Five subjects had BMI within the normal

Table 2 Body composition by dual energy X-ray absorptiometry (DEXA) scan

\begin{tabular}{|c|c|c|c|c|c|c|}
\hline Variable & $\begin{array}{l}\geq 30 \% \text { Body Fat } \\
N=8\end{array}$ & $\begin{array}{l}<30 \% \text { Body Fat } \\
N=2\end{array}$ & $P$-Value & $\begin{array}{l}\leq 60 \% \text { Lean Muscle Mass } \\
N=4\end{array}$ & $\begin{array}{l}>60 \% \text { Lean Muscle Mass } \\
N=6\end{array}$ & $P$-value \\
\hline $\begin{array}{l}\text { Mean Age, years } \pm \text { Standard } \\
\text { deviation (SD) }\end{array}$ & $16.3 \pm 2.7$ & $12.5 \pm 3.5$ & 0.4 & $15.7 \pm 4$ & $15.3 \pm 2.7$ & 0.8 \\
\hline African American, n & 6 & 2 & 0.4 & 4 & 4 & 0.2 \\
\hline Years of SLE $\pm S D$ & $4.1 \pm 2.5$ & $4.5 \pm 0.7$ & 0.7 & $3.3 \pm 1.6$ & $5.5 \pm 2.6$ & 0.2 \\
\hline \multicolumn{7}{|l|}{$\begin{array}{l}\text { Physically Active in the } \\
\text { past year }\end{array}$} \\
\hline Yes & 6 & 2 & 0.9 & 2 & 6 & 0.1 \\
\hline No & 2 & 0 & & 2 & 0 & \\
\hline \multicolumn{7}{|l|}{ Malar rash } \\
\hline Present & 6 & 0 & 0.1 & 4 & 2 & 0.07 \\
\hline Absent & 2 & 2 & & 0 & 4 & \\
\hline \multicolumn{7}{|l|}{ Kidney Disease } \\
\hline Present & 4 & 1 & 0.9 & 4 & 1 & 0.04 \\
\hline Absent & 4 & 1 & & 0 & 5 & \\
\hline \multicolumn{7}{|l|}{ dsDNA Antibody } \\
\hline Present & 8 & 1 & 0.2 & 4 & 5 & 0.9 \\
\hline Absent & 0 & 1 & & 0 & 1 & \\
\hline \multicolumn{7}{|l|}{ Ro/La Antibodies } \\
\hline Present & 2 & 0 & 0.9 & 1 & 1 & 0.9 \\
\hline Absent & 6 & 2 & & 3 & 5 & \\
\hline \multicolumn{7}{|l|}{ Smith Antibody } \\
\hline Present & 3 & 0 & 0.9 & 3 & 0 & 0.03 \\
\hline Absent & 5 & 2 & & 1 & 6 & \\
\hline \multicolumn{7}{|l|}{ Low C3/C4 } \\
\hline Present & 2 & 0 & 0.9 & 2 & 0 & 0.1 \\
\hline Absent & 6 & 2 & & 2 & 6 & \\
\hline Mean SLEDAI, \pm SD & $1.3 \pm 1.1$ & 0 & 0.06 & $2 \pm 1.4$ & $0.4 \pm 0.2$ & 0.07 \\
\hline \multicolumn{7}{|l|}{ Prednisone } \\
\hline Taking & 4 & 0 & 0.4 & 3 & 1 & 0.1 \\
\hline Not taking & 4 & 2 & & 1 & 5 & \\
\hline $\begin{array}{l}\text { Cumulative prednisone } \\
\text { dose, mg (range) }\end{array}$ & $900(0-3600)$ & 0 & 0.1 & $1725(0-3600)$ & $50(0-300)$ & 0.1 \\
\hline \multicolumn{7}{|l|}{ Hydroxychloroquine } \\
\hline Taking & 8 & 2 & - & 4 & 6 & - \\
\hline \multicolumn{7}{|l|}{ Not taking } \\
\hline \multicolumn{7}{|l|}{ Methotrexate } \\
\hline Taking & 2 & 0 & 0.9 & 1 & 1 & 0.9 \\
\hline Not taking & 6 & 2 & & 3 & 5 & \\
\hline \multicolumn{7}{|l|}{ Mycophenolate mofetil } \\
\hline Taking & 3 & 1 & 0.9 & 2 & 2 & 0.9 \\
\hline Not taking & 5 & 1 & & 2 & 4 & \\
\hline
\end{tabular}


range, three were classified as overweight, and two were obese.

Eighty nine percent of female subjects had a body percent fat above $30 \%$. Mean body fat percent was elevated in the entire cohort with a mean of $36.7 \%$ (range in all 9-50.7 \%), and mean of $39.7 \%$ in the nine females (range 25.7-50.7\%). Lean muscle mass ranged from 49.2 to $91 \%$ with a mean of $63.3 \%$. Forty percent of participants had lower than $60 \%$ muscle mass for their age/gender. These same four subjects were also noted to have elevated body fat ( $>=30 \%$ ). We performed exploratory analyses to identify factors associated with abnormal body composition (Table 2). Participants with renal disease were more likely to have low muscle mass compared to those without renal disease $(p=0.04)$. The presence of Smith antibody was associated with higher muscle mass $(p=0.03)$.

$\mathrm{CV}$ endurance was reported as estimated maximal oxygen consumption $\left(\mathrm{VO}_{2} \mathrm{max}\right)$. All participants had low $\mathrm{VO}_{2}$ max measurements compared to data from age and gender matched normal controls. Eighty percent of subjects scored at $<2^{\text {nd }}$ percentile compared to healthy controls while the remaining $20 \%$ of SLE subjects scored between the $2^{\text {nd }}$ and $5^{\text {th }}$ percentile. In regression analysis, the presence of kidney disease was associated with worse $\mathrm{VO}_{2}$ max measurements (Coef: $-10, p=0.007$ ) (Table 3).

Isometric muscle strength testing was performed on dominant elbow and knee. In elbow testing, at 60 degrees/second, only one participant reached goal percentiles (male subject). All other participants were significantly weaker than normal controls, ranging from 10 to $20 \%$ below goal. At 120 degrees/second, none of the participants reached published goals; however, the

Table 3 Regression analysis of cardiovascular endurance

\begin{tabular}{lll}
\hline Variable & Coefficient & $P$-value \\
\hline Age, years & 0.5 & 0.5 \\
African American Race & -9.7 & 0.06 \\
Years of SLE & 0.2 & 0.06 \\
Physically Active & 7.7 & 0.2 \\
Malar rash & -5.6 & 0.2 \\
Kidney Disease & -10 & $\mathbf{0 . 0 0 7}$ \\
dsDNA positive, & -11.6 & 0.1 \\
Ro/La positive & -1.5 & 0.8 \\
Smith positive & -9.9 & $\mathbf{0 . 0 2}$ \\
Low C3/C4 & -10.4 & $\mathbf{0 . 0 4}$ \\
Prednisone & -9.1 & $\mathbf{0 . 0 2}$ \\
Methotrexate & -1.5 & 0.8 \\
Mycophenolate mofetil & -6.5 & 0.1 \\
Body Fat $>30 \%$ & -5.4 & 0.3 \\
Muscle mass $>60 \%$ & 9.7 & $\mathbf{0 . 0 1}$ \\
\hline
\end{tabular}

difference between actual to goal results was much closer (1-10\%). With knee strength testing, no SLE participant reached normal goal values (deficit $2-58 \%$ at 60 degrees/second and deficit $10-30 \%$ at 180 degrees/ second).

\section{Conclusions}

In this study, we found significant deficits in muscle strength and CV endurance. These data are in line with previous studies that have found that adults with SLE have diminished muscle and aerobic capacity compared to age-matched controls $[8,9]$.

Body composition is known to negatively affect quality of life in SLE. In a study of 202 pediatric SLE patients, investigators compared health related quality of life between obese, defined as BMI $\geq 95^{\text {th }}$ percentile for age and gender, and non-obese patients [14]. Obese pediatric SLE patients had significantly worse school function, impaired physical function, and significantly more pain/ hurt compared to non-obese pediatric SLE patients and historical normal controls [14]. In a study of 138 adult women with SLE, obesity as defined by DEXA scan was associated with significant cognitive impairment and decreased executive function, although the mechanism for this relationship is not completely clear [23].

Cardiovascular endurance has been measured in adults with SLE. In 34 women with SLE, lower aerobic capacity was found in patients compared to controls [9]. There was no correlation between $\mathrm{CV}$ endurance and disease activity or medications. In our cohort, $\mathrm{CV}$ endurance was significantly decreased, with all of our subjects testing below the $5^{\text {th }}$ percentile of normal children. This low CV endurance could put children with SLE at increased risk of cardiovascular disease.

Some participants in our study had normal muscle mass, but muscle strength was decreased in the majority. In adults with SLE, both isometric and dynamic muscle strength has been shown to be decreased compared to healthy adults. In a study of 146 women with SLE, muscle mass did not correlate with muscle strength measurements, and reduced lower extremity muscle strength was associated with worse self-reported physical disability [24]. In a longitudinal study of these same women, muscle measurements were repeated approximately 2 years apart [25]. Reduced lower extremity muscle strength predicted clinically significant decreases in physical function, particular among the weakest subjects. Our findings are particularly worrisome for the pediatric SLE population as significant deficits in muscle strength could lead to reduced physical function and activity.

There are some limitations to our study including small sample size, cross-sectional analysis, and exclusion of SLE subjects with active arthritis or myositis. The 
subjects in our cohort had relatively low disease activity and this may bias our findings, particularly in body composition associations. We used published normative values for control data and this lack of a local comparative group may be a weakness. This is a small sample size and the regression analyses should be interpreted with caution and used as hypothesis-generating for future studies. The strengths of our study include complete body composition, exercise capacity, and muscle strength testing data obtained during the same visit.

Our study reinforced published data of increased body fat and low muscle mass in pediatric patients with SLE. Despite low SLE disease activity, the subjects in our cohort had significant deficits in CV endurance and muscle strength. Clinicians should consider focusing on exercise programs that can increase aerobic capacity in this highrisk population.

\section{Acknowledgements}

The authors would like to acknowledge Kerry Stewart, EdD, for his input and guidance in this study regarding Biodex and isometric muscle strength testing.

\section{Funding}

1. Thomas Wilson Sanitarium for Children of Baltimore City, PI: Sule, Sangeeta.

2. National Institute of Arthritis and Musculoskeletal and Skin Diseases,

PI: Sule, Sangeeta.

\section{Availability of data and material}

Consent for publication of the dataset was not obtained from participants at the recruitment to the trial because of the small sample size and possibility of participant identification.

\section{Authors' contributions}

SS designed the study, recruited participants, maintained the database, and analyzed the data. KF conceived of the study and analyzed the data. Both authors read and approved the final manuscript.

\section{Competing interests}

The authors declare that they have no competing interests.

\section{Consent for publication}

This manuscript does not contain individual person's data and this is not applicable.

\section{Ethics approval and consent to participate}

Ethics approval was obtained for the study from the Johns Hopkins University Institutional Review Board. Guardians were consented and participants assented to participate in the study.

\section{Author details}

'Department of Pediatrics, Johns Hopkins University, 200 N. Wolfe Street, Suite 2126, Baltimore, MD 21287, USA. ${ }^{2}$ University of Alabama at Birmingham School of Public Health, 1720 2nd Avenue South, RPHB 214C, Birmingham, AL 35294, USA.

Received: 28 June 2016 Accepted: 1 September 2016

Published online: 05 September 2016

\section{References}

1. Ward MM. Premature morbidity from cardiovascular and cerebrovascular diseases in women with systemic lupus erythematosus. Arthritis Rheum. 1999;42(2):338-46

2. Brunner HI, Silverman ED, To T, Bombardier C, Feldman BM. Risk factors for damage in childhood-onset systemic lupus erythematosus: cumulative disease activity and medication use predict disease damage. Arthritis Rheum. 2002;46(2):436-44.

3. Ilowite NT, Samuel P, Ginzler E, Jacobson MS. Dyslipoproteinemia in pediatric systemic lupus erythematosus. Arthritis Rheum. 1988;31(7):859-63.

4. Asanuma $Y$, Oeser A, Shintani AK, Turner E, Olsen N, Fazio S, Linton MF, Raggi $P$, Stein CM. Premature coronary-artery atherosclerosis in systemic lupus erythematosus. N Engl J Med. 2003;349(25):2407-15.

5. Ardoin SP, Schanberg LE, Sandborg C, Yow E, Barnhart HX, Mieszkalski K, llowite NT, von Scheven E, Eberhard A, Levy DM, Kimura Y, Silverman E, Bowyer SL, Punaro L, Singer NG, Sherry DD, McCurdy D, Klein-Gitelman M, Wallace C, Silver R, Wagner-Weiner L, Higgins GC, Brunner HI, Jung LK, Imundo L, Soep JB, Reed AM, APPLE investigators. Laboratory markers of cardiovascular risk in pediatric SLE: the APPLE baseline cohort. Lupus. 2010;19(11):1315-25

6. Schanberg LE, Sandborg C, Barnhart HX, Ardoin SP, Yow E, Evans GW, Mieszkalski KL, llowite NT, Eberhard A, Levy DM, Kimura Y, von Scheven E, Silverman E, Bowyer SL, Punaro L, Singer NG, Sherry DD, McCurdy D, Klein-Gitelman M, Wallace C, Silver R, Wagner-Weiner L, Higgins GC, Brunner HI, Jung L, Soep JB, Reed A. Atherosclerosis Prevention in Pediatric Lupus Erythematosus Investigators. Premature atherosclerosis in pediatric systemic lupus erythematosus: risk factors for increased carotid intima-media thickness in the atherosclerosis prevention in pediatric lupus erythematosus cohort. Arthritis Rheum. 2009;60(5):1496-507.

7. Houghton KM, Tucker LB, Potts JE, McKenzie DC. Fitness, fatigue, disease activity, and quality of life in pediatric lupus. Arthritis Rheum. 2009;59(4):537-5.

8. Eriksson K, Svenungsson E, Karreskog H, Gunnarsson I, Gustafsson J, Moller S, Pettersson S, Bostrom C. Physical activity in patients with systemic lupus erythematosus and matched controls. Scand J Rheumatol. 2012;41(4):290-7.

9. Bostrom C, Dupre B, Tengvar P, Jansson E, Opava CH, Lundberg IE. Aerobic capacity correlates to self-assessed physical function but not to overall disease activity or organ damage in women with systemic lupus erythematosus with low-to-moderate disease activity and organ damage. Lupus. 2008;17(2):100-4.

10. Lilleby V, Haugen M, Morkrid L, Frey Froslie K, Holven KB, Forre O. Body composition, lipid and lipoprotein levels in childhood-onset systemic lupus erythematosus. Scand J Rheumatol. 2007;36(1):40-7.

11. Regio $P$, Bonfa E, Takayama $L$, Pereira $R$. The influence of lean mass in trabecular and cortical bone in juvenile onset systemic lupus erythematosus. Lupus. 2008;17(9):787-92.

12. Caetano M, Terreri MT, Ortiz T, Pinheiro M, Souza F, Sarni R. Bone mineral density reduction in adolescents with systemic erythematosus lupus: association with lack of vitamin D supplementation. Clin Rheumatol. 2015;34(12):2065-70.

13. Sinicato NA, Postal M, Peres FA, Pelicari Kde O, Marini R, dos Santos AO, Ramos CD, Appenzeller S. Obesity and cytokines in childhood-onset systemic lupus erythematosus. J Immunol Res. 2014;2014:162047.

14. Mina R, Klein-Gitelman MS, Nelson S, Eberhard BA, Higgins G, Singer NG, Onel K, Tucker L, O'Neil KM, Punaro M, Levy DM, Haines K, Ying J, Brunner $\mathrm{HI}$. Effects of obesity on health-related quality of life in juvenile-onset systemic lupus erythematosus. Lupus. 2015;24(2):191-7.

15. Tan EM, Cohen AS, Fries JF, Masi AT, McShane DJ, Rothfield NF, et al. The 1982 revised criteria for the classification of systemic lupus erythematosus. Arthritis Rheum. 1982;25(11):1271-7.

16. Hochberg MC. Updating the American College of Rheumatology revised criteria for the classification of systemic lupus erythematosus [letter]. Arthritis Rheum. 1997;40(9):1725.

17. Schned ES, Glickstein SL, Doyle MA. Derivation of the SLEDAI [letter] Arthritis Rheum. 1993;36(6):877-8.

18. Eisenmann JC, Laurson KR, Welk GJ. Aerobic fitness percentiles for U.S adolescents. Am J Prev Med. 2011;41(4 Suppl 2):S106-10

19. Laurson KR, Eisenmann JC, Welk GJ. Development of youth percent body fat standards using receiver operating characteristic curves. Am J Prev Med. 2011;41(4 Suppl 2):S93-9.

20. Laurson KR, Eisenmann JC, Welk GJ. Body fat percentile curves for U.S children and adolescents. Am J Prev Med. 2011;41(4 Suppl 2):S87-92.

21. Welk GJ, Laurson KR, Eisenmann JC, Cureton KJ. Development of youth aerobic-capacity standards using receiver operating characteristic curves. Am J Prev Med. 2011;41(4 Suppl 2):S111-6. 
22. Ogden CL, Li Y, Freedman DS, Borrud LG, Flegal KM. Smoothed percentage body fat percentiles for U.S. children and adolescents, 1999-2004. Natl Health Stat Report. 2011;43(43):1-7.

23. Katz P, Julian L, Tonner MC, Yazdany J, Trupin L, Yelin E, Criswell LA. Physical activity, obesity, and cognitive impairment among women with systemic lupus erythematosus. Arthritis Care Res (Hoboken). 2012;64(4):502-10.

24. Andrews JS, Trupin L, Schmajuk G, Barton J, Margaretten M, Yazdany J, Yelin EH, Katz PP. Muscle strength, muscle mass, and physical disability in women with systemic lupus erythematosus. Arthritis Care Res (Hoboken). 2015;67(1):120-7.

25. Andrews JS, Trupin L, Schmajuk G, Barton J, Margaretten M, Yazdany J, Yelin EH, Katz PP. Muscle strength and changes in physical function in women with systemic lupus erythematosus. Arthritis Care Res (Hoboken). 2015;67(8):1070-7.

Submit your next manuscript to BioMed Central and we will help you at every step:

- We accept pre-submission inquiries

- Our selector tool helps you to find the most relevant journal

- We provide round the clock customer support

- Convenient online submission

- Thorough peer review

- Inclusion in PubMed and all major indexing services

- Maximum visibility for your research

Submit your manuscript at www.biomedcentral.com/submit
Biomed Central 